\title{
Article
}

\section{The Effects of Barefoot and Shod Running on Limb and Joint Stiffness Characteristics in Recreational Runners.}

Sinclair, Jonathan Kenneth, Atkins, Stephen and Taylor, Paul John Available at http://clok.uclan.ac.uk/11945/

Sinclair, Jonathan Kenneth ORCID: 0000-0002-2231-3732, Atkins, Stephen and Taylor, Paul John ORCID: 0000-0002-9999-8397 (2015) The Effects of Barefoot and Shod Running on Limb and Joint Stiffness Characteristics in Recreational Runners. Journal of Motor Behavior, 1 (7).

It is advisable to refer to the publisher's version if you intend to cite from the work.

For more information about UCLan's research in this area go to http://www.uclan.ac.uk/researchgroups/ and search for <name of research Group>.

For information about Research generally at UCLan please go to http://www.uclan.ac.uk/research/

All outputs in CLoK are protected by Intellectual Property Rights law, including Copyright law. Copyright, IPR and Moral Rights for the works on this site are retained by the individual authors and/or other copyright owners. Terms and conditions for use of this material are defined in the policies page. 
RESEARCH ARTICLE

The Effects of Barefoot and Shod Running on Limb and Joint Stiffness Characteristics in Recreational Runners

Jonathan Sinclair ${ }^{1}$, Stephen Atkins ${ }^{1}$, Paul J. Taylor ${ }^{2}$

$5{ }^{1}$ Centre for Applied Sport and Exercise Sciences, School of Sport Tourism and Outdoors, University of Central Lancashire, Preston, England. ${ }^{2}$ School of Psychology, University of Central Lancashire, Preston, England.

ABSTRACT. The authors aimed to determine the effects of barefoot (BF) and several commercially available barefoot-inspired (BFIS) footwear models on limb and joint stiffness characteristics

10 compared with conventional footwear $(\mathrm{CF})$. Fifteen male participants ran over a force platform at $4.0 \mathrm{~m} . \mathrm{s}^{-1}$, in BF, BFIS, and CF conditions. Measures of limb and joint stiffness were calculated for each footwear. The results indicate that limb and knee stiffness were greater in $\mathrm{BF}$ and minimalist BFIS than in $\mathrm{CF}$. CF and more

15 structured BFIS were associated with a greater ankle stiffness compared with $\mathrm{BF}$ and minimalist BFIS. These findings serve to provide further insight into the susceptibility of runners to different injury mechanisms as a function of footwear.

Keywords: barefoot, stiffness, running, biomechanics

$\mathbf{R}^{\mathrm{c}}$ esearch interest into the biomechanics of barefoot (BF) running has expanded considerably in recent years. The increase in popularity of BF running is based on the pretext that the absence of footwear is more natural and may also be associated with a reduced incidence of chronic

25 injuries when compared with traditional running footwear (Lieberman et al., 2010). In response to the recent interest in BF running, new footwear models have been developed that are designed to integrate the benefits of running $\mathrm{BF}$ into a shod condition (Sinclair, Hobbs, Currigan, \& Taylor,

30 2013). Several BF-inspired shoe (BFIS) models are now commercially available and vary considerably in terms of their design characteristics from minimalistic to more structured designs that offer some degree of midsole interface (Sinclair, Greenhalgh, Edmundson, Brooks, \& Hobbs,

35 2013; Sinclair, Hobbs et al., 2013).

The importance of lower extremity limb stiffness is now recognized in biomechanical literature, as we seek to gain more insight into the mechanics of human locomotion and obtain more clinically relevant information regarding the

40 etiology of chronic lower limb injuries (Butler, Crowell, \& Davis, 2003). Stiffness is a reflection of the force applied to a body and the resultant deformation of that body (Latash \& Zatsiorsky, 1993). During landing movements such as running, the support limb is modeled using a spring mass

45 system (Blickhan, 1989), whereby the stance limb is indicative of a linear spring and the body mass is representative of the point mass (McMahon \& Cheng 1990). The stance limb spring is able to shorten and lengthen as lower extremity joints flex and extend (Farley \& Morgenroth, 1999).

50 Limb stiffness during running has been associated with both performance and injury etiology (Dutto \& Smith, 2002; Granata, Padua, \& Wilson, 2001; Kerdock,
Biewener, McMahon, Weyand, \& Herr, 2002; Williams, McClay Davis, Scholz, Hamill, \& Buchanan, 2003). Limb stiffness is required for energy to be stored and released during the stance phase as a function of the stretch-shorten reflex (Arampatzis, Bruggemann, \& Metzler, 1999). Indeed, higher levels of stiffness at the lower extremity joints during the absorption phase of running have been shown to effectively precondition the muscle-tendon units to store and utilize energy more effectively, which enhances mechanical efficiency and power during the push-off phase (Kyrolainen, Belli, \& Komi, 2001). With regards to clinical effects, lower than optimal levels of limb stiffness have been associated with an enhanced susceptibility to soft tissue injuries, whereas higher leg stiffness indices have been linked to an increased risk of bone-related injuries (McMahon, Comfort, \& Pearson, 2012).

In addition to limb stiffness it has also been suggested that the stiffness characteristics of the individual lower extremity joints be considered (Hamill et al., 2009). Measures of joint stiffness are important as they can be related to the attenuation of load transmission through the musculoskeletal system (Hamill et al., 2014). Joint stiffness is a reflection of the joint moment-angle relationship and can be modeled as a torsional spring system (Williams et al., 2003). Clinically, increased joint stiffness has also been linked to the etiology of chronic injuries as higher stiffness leads to an enhanced load imposed on the joint comparison to a more compliant joint (Hamill et al., 2009).

The mechanics of running BF and BFIS have been examined extensively to better understand the biomechanical effects of running without shoes. To date, the effects of BF and BFIS on limb stiffness characteristics have received little attention in biomechanical research. Several investigations have confirmed that running $\mathrm{BF}$ is associated with significantly greater limb stiffness in relation to conventional running shoes (CF; De Wit, De Clercq, \& Aerts, 2000; Divert, Baur, Mornieux, Mayer, \& Belli, 2005; Shih, Lin, \& Shiang, 2013). Only one study however, has examined the effects of BFIS. Lussiana, Hébert-Losier, and Mourot (2014) demonstrated that limb stiffness was significantly larger in BFIS in comparison with $\mathrm{CF}$.

Correspondence address: Jonathan Sinclair, Centre for Applied Sport and Exercise Sciences, School of Sport Tourism and Outdoors, University of Central Lancashire, Preston, Lancashire PR12HE, United Kingdome-mail: jksinclair@uclan.ac.uk 
However, while the effects of BF and BFIS on limb 95 stiffness parameters have previously been investigated, researchers did not consider the stiffness parameters of the lower extremity joints. The aim of the present investigation was to determine the effects of $\mathrm{BF}$ and several commercially available BFIS models on limb and joint

100 stiffness characteristics in comparison to CF. In this study we tested the hypothesis that (a) running BF and in minimalist BFIS would be associated with significantly greater limb stiffness compared to $\mathrm{CF}$ and (ii) knee joint stiffness would significantly larger when running $\mathrm{BF}$ and in mini-

105 malist BFIS in comparison to $\mathrm{CF}$, whereas ankle stiffness would be greater in CF.

\section{Method}

\section{Participants}

Fifteen male runners, completing at least $35 \mathrm{~km}$ per 110 week, volunteered to take part in this study. All were free from musculoskeletal pathology at the time of data collection and provided written informed consent. All participants were nonhabitual BF runners and deemed to exhibit a heeltoe running pattern as they demonstrated an impact peak in

115 their vertical ground reaction force time curve when wearing conventional footwear (Cavanagh \& Lafortune, 1980). The mean characteristics of the participants were the following: age $23.5 \pm 2.5$ years, height $1.75 \pm 0.05 \mathrm{~m}$, and body mass $72.2 \pm 6.7 \mathrm{~kg}$. The procedure utilized for this

120 investigation was approved by the University of Central Lancashire, School of Sport Tourism and Outdoors, ethical committee in agreement with the principles outlined in the declaration of Helsinki. No external funding was provided by any of the footwear manufacturers examined in this 125 investigation.

\section{Experimental Footwear}

The shoes utilized during this study consisted of a Saucony Pro Grid Guide II, Vibram Five Fingers, Vivo barefoot Ultra, Merrell Bare Access, Inov-8 Evoskin, and Nike

130 Free 3.0. The shoes were the same for all runners; they differed in size only (sizes 7-10 in men's UK shoe sizes). In accordance with previous recommendations the Vibram Five Fingers, Merrell, and Inov- 8 were considered to be minimalist BFIS and the Nike Free and Vivo were classi-

135 fied as structured BFIS (Sinclair, 2014; Sinclair, Hobbs et al., 2013).

\section{Procedure}

Participants ran at $4.0 \mathrm{~m} . \mathrm{s}^{-1}$, striking a force platform (Kistler, Kistler Instruments Ltd., Alton, England; length,

140 width, height $=0.6 \times 0.4 \times 0.0 \mathrm{~m}$ ) embedded in the floor (Altrosports $6 \mathrm{~mm}$, Altro Ltd,) with their right foot (Sinclair, Hobbs, Taylor, Currigan, \& Greenhalgh,
2014). The force platform sampled at $1000 \mathrm{~Hz}$. Running velocity was quantified using Newtest 300 infrared timing gates (Newtest, Oy Koulukatu, Finland), and a maximum deviation of $\pm 5 \%$ from the predetermined velocity was allowed. The stance phase was delineated as the duration over which $>20 \mathrm{~N}$ of vertical force was applied to the force platform (Sinclair, Edmundson, Brooks, \& Hobbs, 2011). Runners completed five successful trials in each footwear condition. A successful trial was defined as one within the specified velocity range and where the foot made full contact with the force plate and no evidence of gait modifications due to the experimental conditions. The order in which participants ran in each footwear condition was randomized.

Kinematics and ground reaction force (GRF) data were synchronously collected. Kinematic data were captured at $250 \mathrm{~Hz}$ via an eight-camera motion analysis system (Qualisys Medical AB, Goteborg, Sweden). Lower extremity segments were modeled in 6-DOF using the calibrated anatomical systems technique (Cappozzo, Catani, Leardini, Benedeti, \& Della, 1995). To define the segment coordinate axes of the right shank and thigh, retroreflective markers were placed unilaterally onto medial and lateral malleoli, medial and lateral epicondyles of the femur, and also the greater trochanter. Carbon fiber tracking clusters were positioned onto the shank and thigh segments. Static calibration trials were obtained allowing for the anatomical markers to be referenced in relation to the tracking markers and clusters. The $\mathrm{Z}$ (transverse) axis was oriented vertically from the distal segment end to the proximal segment end. The Y (coronal) axis was oriented in the segment from posterior to anterior. Finally, the $\mathrm{X}$ (sagittal) axis orientation was determined using the right hand rule and was oriented from medial to lateral.

\section{Data Processing}

Retroreflective markers were digitized using Qualisys Track Manager to identify markers and then exported as C3D files to Visual 3D (C-Motion, Germantown, MD). GRF and retroreflective marker trajectories were filtered at 50 and $12 \mathrm{~Hz}$, respectively, using a low-pass Butterworth fourth-order zero-lag filter (Sinclair, 2014). Knee and ankle joint kinematics were calculated using an XYZ sequence of rotations (where $\mathrm{X}$ represents sagittal plane, $\mathrm{Y}$ represents coronal plane, and $\mathrm{Z}$ represents transverse plane rotations; Sinclair, Taylor, Edmundson, Brooks, \& Hobbs, 2012). Newton-Euler inverse dynamics were also adopted, which allowed knee and ankle joint moments to be calculated. To quantify joint moments, segment mass, segment length, GRF, and angular kinematics were utilized. All kinematic waveforms were normalized to $100 \%$ of the stance phase before processed trials were averaged within subjects. Discrete kinematic measures from the knee and ankle extracted for statistical analysis were (a) angle at footstrike, (b) peak 
angle, (c) joint angular excursion (representing the angular displacement from footstrike to peak angle), and (d) peak joint moment.

200 Estimation of limb stiffness during running used a mathematical spring-mass model (Blickhan, 1989). Limb stiffness was calculated from the ratio of the peak vertical GRF to the maximum compression of the leg spring which was calculated as the change in thigh length from footstrike to

205 minimum thigh length during the stance phase (Farley \& Morgenroth, 1999). The torsional stiffness of the knee and ankle joints were calculated as a function of the ratio of the change in sagittal joint moment to joint angular excursion in the sagittal plane between the beginning of the ground

210 contact phase and the instant when the joints were maximally flexed (Farley \& Morgenroth, 1999). Limb/joint stiffness and joint moment parameters were normalized to body mass. Limb stiffness was expressed as N.kg.m ${ }^{-1}$, joint moments as Nm.kg ${ }^{-1}$, and joint stiffness as Nm.kg ${ }^{-1} \cdot \mathrm{rad}^{-1}$.

\section{Statistical Analysis}

Differences in limb and joint stiffness parameters across all of the different footwear conditions were examined using one-way repeated measures ANOVAs, with significance accepted at the $p \leq .05$ level. Effect sizes were calcu-

220 lated using partial omega ${ }^{2}\left(\mathrm{p} \omega^{2}\right)$. Post hoc pairwise comparisons were conducted on all significant main effects. The data was screened for normality using a Shapiro-Wilk test, which confirmed that the normality assumption was met. All statistical actions were conducted using SPSS ver-

225 sion 22.0 (SPSS Inc., Chicago, IL).

\section{Results}

Table 1 and Figures 1-2 present the footwear differences in limb and joint stiffness. The results also indicate that the experimental footwear significantly affected limb and knee 230 joint stiffness parameters.

\section{Joint Kinematics}

At the knee a main effect $\left(p \leq .05, \mathrm{p} \omega^{2}=.33\right)$ was shown for knee angle at footstrike. Post hoc analysis showed the $\mathrm{BF}$ condition exhibited greater flexion at footstrike than the

$235 \mathrm{CF}$, Nike Free, and Vivo footwear (Table 1, Figure 1a). There was also a main effect $\left(p \leq .05, \mathrm{p} \omega^{2}=.28\right)$ noted for knee excursion. Post hoc analysis revealed that excursion was larger in the $\mathrm{CF}$ and Nike Free conditions compared with BF (Table 1, Figure 1a). Finally a main effect ( $p \leq$

$\left.240.05, \mathrm{p} \omega^{2}=.29\right)$ for the peak knee extensor moment. Post hoc analysis indicated that the peak moment was greater in the $\mathrm{CF}$ and Nike Free footwear in comparison with BF (Table 1, Figure 1b).

At the ankle a main effect $\left(p \leq .05, \mathrm{p} \omega^{2}=.28\right)$ was 245 shown for the angle at footstrike. Post hoc analysis showed that the $\mathrm{BF}$ condition was associated with a more plantarflexed ankle position compared with the $\mathrm{CF}$ and Nike Free footwear (Table 1, Figure 1c). In addition a main effect $\left(p \leq .05, \mathrm{p} \omega^{2}=.29\right)$ was shown for peak dorsiflexion. Post hoc analysis showed that the BF and Inov-8 conditions exhibited a larger peak dorsiflexion compared with the CF, Nike Free, Vivo, and Merrell footwear (Table 1, Figure 1c). There was also a main effect $(p \leq .05$, $\mathrm{p} \omega^{2}=.62$ ) for ankle excursion. Post hoc analysis revealed that ankle excursion was larger in the BF and Inov-8 conditions compared with the CF, Nike Free, and Vivo footwear (Table 1, Figure 1c). Finally a main effect $\left(p \leq .05, \mathrm{p} \omega^{2}=\right.$ .61) for the peak ankle plantarflexor moment. Post hoc analysis indicated that ankle plantarflexor moments were larger in the BF and Inov-8 conditions compared with the $\mathrm{CF}$ and Nike Free footwear (Table 1, Figure 1d).

\section{Spring Mass Characteristics}

A main effect $\left(p \leq .05, \mathrm{p} \omega^{2}=.22\right)$ was shown for limb compression. Post hoc analysis revealed that limb compression was larger in the $\mathrm{CF}$ and Nike Free footwear compared with the $\mathrm{BF}$ and Inov-8 conditions (Table 1, Figure 2b). In addition a main effect ( $p \leq .05$, $\mathrm{p} \omega^{2}=.23$ ) was observed for limb stiffness. Post hoc analysis revealed that limb stiffness was larger in the $\mathrm{BF}$, Inov-8, and Merrell conditions compared with the $\mathrm{CF}$ and Nike Free footwear (Table 1, Figure 2a). There was also a main effect $\left(p \leq .05, \mathrm{p} \omega^{2}=.22\right)$ for knee stiffness. Post hoc analysis revealed that knee stiffness in the $\mathrm{BF}$ condition was larger than the $\mathrm{CF}$ and Nike Free footwear (Table 1, Figure 2c). Finally, a main effect ( $p \leq .05, \mathrm{p} \omega^{2}=.23$ ) was observed for ankle stiffness. Post hoc analysis revealed that ankle stiffness was larger in the $\mathrm{CF}$, Nike Free, and Vivo footwear compared with the BF and Inov-8 conditions (Table 1, Figure 2d).

\section{Discussion}

In the present investigation we aimed to determine the effects of BF and BFIS on limb and joint stiffness parameters in comparison to $\mathrm{CF}$. There is presently little published research concerning the effects of BF and BFIS on limb and joint stiffness characteristics during running. The current investigation provides additional information by comparatively examining the limb and joint stiffness characteristics of running in BF and BFIS compared to $\mathrm{CF}$.

The first key finding from the current investigation is that limb stiffness was shown to be larger when running BF and in minimalist BFIS in comparison to CF and more structured BFIS. This observation is in agreement with our hypothesis and concurs with the observations of De Wit et al. (2000), Divert et al. (2005), Shih et al. (2013), and Lussiana et al. (2014), who also reported significant increases in limb stiffness when running BF and in BFIS. It 
TABLE 1. Limb and Joint Stiffness Characteristics as a Function of Different Footwear

\begin{tabular}{|c|c|c|c|c|c|c|c|c|c|c|c|c|c|c|c|}
\hline & \multicolumn{2}{|c|}{ Barefoot } & \multicolumn{2}{|c|}{ Conventional } & \multicolumn{2}{|c|}{$\begin{array}{l}\text { Vibram } \\
\text { Five } \\
\text { Fingers }\end{array}$} & \multicolumn{2}{|c|}{ Inov-8 } & \multicolumn{2}{|c|}{ Merrell } & \multicolumn{2}{|c|}{$\begin{array}{l}\text { Nike } \\
\text { Free }\end{array}$} & \multicolumn{3}{|c|}{ Vivo } \\
\hline & $M$ & $S D$ & $M$ & $S D$ & $M$ & $S D$ & $M$ & $S D$ & $M$ & $S D$ & $M$ & $S D$ & $M$ & $S D$ & \\
\hline $\begin{array}{l}\text { Knee } \\
\text { footstrike } \\
\text { (rad) }\end{array}$ & 0.25 & 0.1 & 0.14 & 0.11 & 0.21 & 0.13 & 0.23 & 0.11 & 0.19 & 0.12 & 0.11 & 0.13 & 0.11 & 0.17 & $*$ \\
\hline $\begin{array}{l}\text { Knee } \\
\text { peak flexion } \\
\text { (rad) }\end{array}$ & 0.64 & 0.14 & 0.64 & 0.14 & 0.66 & 0.15 & 0.65 & 0.14 & 0.62 & 0.13 & 0.61 & 0.13 & 0.57 & 0.15 & \\
\hline $\begin{array}{l}\text { Knee } \\
\quad \text { excursion } \\
\quad(\mathrm{rad})\end{array}$ & 0.39 & 0.07 & 0.5 & 0.06 & 0.45 & 0.05 & 0.42 & 0.06 & 0.44 & 0.09 & 0.5 & 0.09 & 0.46 & 0.12 & $*$ \\
\hline $\begin{array}{l}\text { Ankle } \\
\text { footstrike } \\
\text { (rad) }\end{array}$ & -0.01 & 0.2 & 0.12 & 0.16 & 0.03 & 0.12 & 0.03 & 0.16 & 0.03 & 0.17 & 0.12 & 0.11 & 0.05 & 0.18 & $*$ \\
\hline $\begin{array}{l}\text { Ankle peak } \\
\text { dorsiflexion } \\
(\mathrm{rad})\end{array}$ & 0.38 & 0.12 & 0.32 & 0.11 & 0.33 & 0.12 & 0.4 & 0.12 & 0.28 & 0.11 & 0.3 & 0.13 & 0.29 & 0.12 & $*$ \\
\hline $\begin{array}{l}\text { Ankle } \\
\text { excursion } \\
\text { (rad) }\end{array}$ & 0.39 & 0.12 & 0.2 & 0.1 & 0.3 & 0.09 & 0.37 & 0.11 & 0.26 & 0.14 & 0.18 & 0.06 & 0.24 & 0.11 & $*$ \\
\hline $\begin{array}{l}\text { Limb } \\
\quad \text { compression }(\mathrm{m})\end{array}$ & 0.04 & 0.01 & 0.05 & 0.01 & 0.04 & 0.01 & 0.04 & 0.01 & 0.04 & 0.01 & 0.05 & 0.01 & 0.05 & 0.01 & $*$ \\
\hline GRF (N.kg $\left.{ }^{-1}\right)$ & 21.41 & 3.35 & 21.15 & 3.56 & 21.28 & 3.03 & 21.13 & 2.66 & 21.87 & 4.72 & 19.94 & 3.88 & 21.44 & 2.77 & \\
\hline $\begin{array}{l}\text { Knee } \\
\quad \text { moment } \\
\left(\mathrm{Nm}_{\mathrm{kg}}{ }^{-1}\right)\end{array}$ & 2.63 & 0.81 & 2.91 & 0.78 & 2.76 & 0.77 & 2.75 & 0.90 & 2.82 & 0.67 & 2.88 & 0.64 & 2.72 & 0.87 & $*$ \\
\hline $\begin{array}{l}\text { Ankle } \\
\text { moment } \\
\left(\mathrm{Nm}_{\mathrm{kg}}{ }^{-1}\right)\end{array}$ & -2.54 & 0.40 & -2.32 & 0.48 & -2.50 & 0.41 & -2.55 & 0.46 & -2.43 & 0.62 & -2.30 & 0.58 & -2.55 & 0.68 & \\
\hline $\begin{array}{l}\text { Limb } \\
\text { stiffness } \\
\quad\left(\mathrm{Nkg} \cdot \mathrm{m}^{-1}\right)\end{array}$ & 610.21 & 210.34 & 460.17 & 140.54 & 560.38 & 110.87 & 620.48 & 280.22 & 680.77 & 470.53 & 480.89 & 260.34 & 490.11 & 140.79 & $*$ \\
\hline $\begin{array}{l}\text { Knee } \\
\quad \text { stiffness } \\
\quad\left(\mathrm{Nm}_{\mathrm{kg}}{ }^{-1} \cdot \mathrm{rad}^{-1}\right)\end{array}$ & 7.07 & 2.78 & 5.88 & 1.34 & 6.28 & 1.44 & 6.57 & 1.84 & 6.68 & 1.88 & 5.79 & 1.26 & 5.96 & 2.30 & $*$ \\
\hline $\begin{array}{l}\text { Ankle } \\
\quad \text { stiffness } \\
\quad\left(\mathrm{Nm}_{\mathrm{kg}}{ }^{-1} \cdot \mathrm{rad}^{-1}\right)\end{array}$ & 7.21 & 1.52 & 11.72 & 5.84 & 9.35 & 2.42 & 7.31 & 2.11 & 11.13 & 4.26 & 13.52 & 2.43 & 11.32 & 2.80 & $*$ \\
\hline
\end{tabular}

is proposed that this observation relates to the decrease in 300 limb compression noted during BF and minimalist conditions which in conjunction with the similar GRF values observed between footwear leads to higher limb stiffness.

It is proposed that decreases in limb compression were caused by the reduced stance times typically asso305 ciated with BF and BFIS compared with the CF. Morin, Samozino, Zameziati, and Belli (2007) and Hamill, Russell, Gruber, and Miller (2011) demonstrated that reduced stance times are associated with increases in limb stiffness, with alterations in contact time associated

310 with up to $90 \%$ of the change in limb stiffness. Clinically, higher levels of limb stiffness have been linked to an increased risk from bone-related injuries, supporting the observations of Sinclair, Hobbs, et al. (2013) and Sinclair, Taylor, and Andrews (2013), who showed significant increases in tibial accelerations when running $\mathrm{BF}$. As such running BF and in minimalist BFIS appears to place runners at increased risk from bone injuries yet increased stiffness may protect from injuries to the soft tissues (McMahon et al., 2012).

In addition, the findings from this study confirmed that knee stiffness was larger in the BF condition compared with the CF and structured BFIS. This observation serves to support our hypothesis and is likely to relate to the reduction in knee excursion noted when running $\mathrm{BF}$, particularly in light of the concurrent reduction in knee extensor moment. Decreased knee excursions noted 

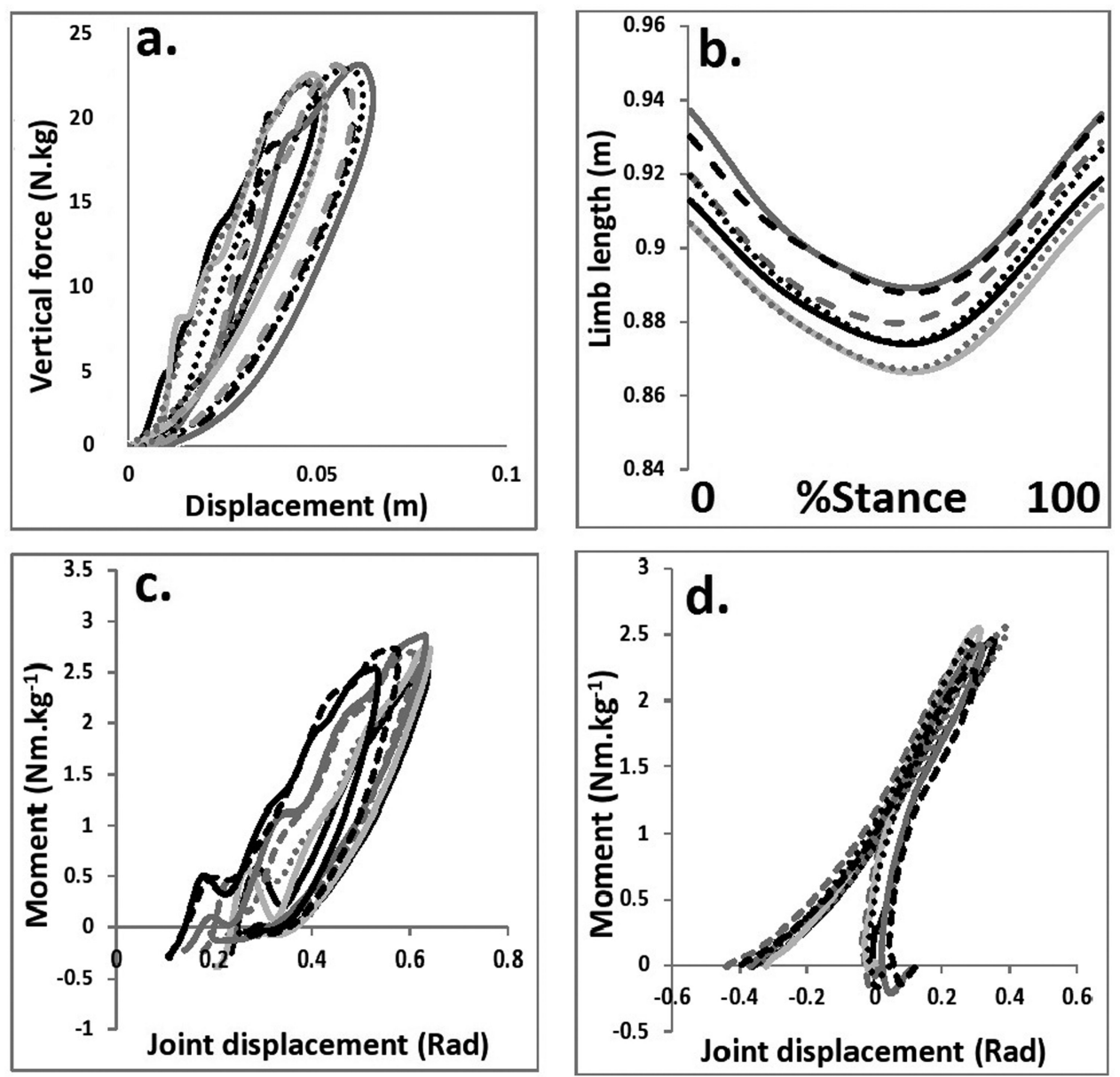

FIGURE 1. Knee and ankle kinetics and kinematics as a function of footwear: (a) = knee angle, (b) = knee extensor moment, (c) $=$ ankle angle, and $(\mathrm{d})=$ ankle plantarflexor moment. $\mathrm{FL}=$ flexion, EXT $=$ extension, DF $=$ dorsiflexion, PF $=$ plantarflexion; barefoot $=$ black, Nike Free $=$ black dash, conventional $=$ dark grey, Vibram five-fingers $=$ light grey, Vivo $=$ dot, Merrell $=$ dark grey dash, Inov-8 = dark grey dot.

when running $\mathrm{BF}$ agree with the observations of Sinclair, Greenhalgh, et al. (2013) and Sinclair, Hobbs, et al. (2013) and may also subsequently relate to the decreased stance phase durations observed when running without shoes. Decreases in stance phase duration facilitates an increase in step frequency which served to reduce the role of the knee joint for energy absorption during the impact phase of running (Kulmala, Avela,

335 Pasanen, \& Parkkari, 2013), thus the flexion range of motion is reduced.

Similarly, in support of our hypothesis the findings show that ankle stiffness was higher in the $\mathrm{CF}$ and structured BFIS conditions. This observation relates to the increase in

340 ankle excursion noted when running BF. Increased ankle excursions were a function of the increases in plantarflexion at footstrike noted when running $\mathrm{BF}$ and in minimalist BFIS (Sinclair, Greenhalgh, Edmundson, Brooks, \& Hobbs, 2013; Sinclair, Hobbs et al., 2013). The increases in knee 345 and ankle moments in the $\mathrm{CF}$ and $\mathrm{BF}$ conditions are in agreement with the findings of Sinclair (2014), who noted similar findings in relation to joint kinetics. Therefore the current investigation also provides further support to the notion that running BF and in minimalist BFIS may attenuate the risk of knee pathologies but also subsequently place runners at increased risk from ankle injuries (Kulmala et al., 2013; Sinclair, 2014).

A limitation of the present study that may reduce its generalizability is that only male runners were examined. Females exhibit distinct kinetics and kinematics when compared to male recreational runners (Ferber, Davis, \& Williams, 2003; Sinclair, Greenhalgh, Edmundson, Brooks, \& Hobbs, 2012b). In addition, women have also been shown to differ in their limb stiffness parameters in relation to males (Granata et al., 2001). This therefore suggests that further investigation using a female sample is warranted. In addition that only nonhabitual BF runners were examined may serve as a limitation to this work. Research investigating the kinetics of BF running in shod populations has 

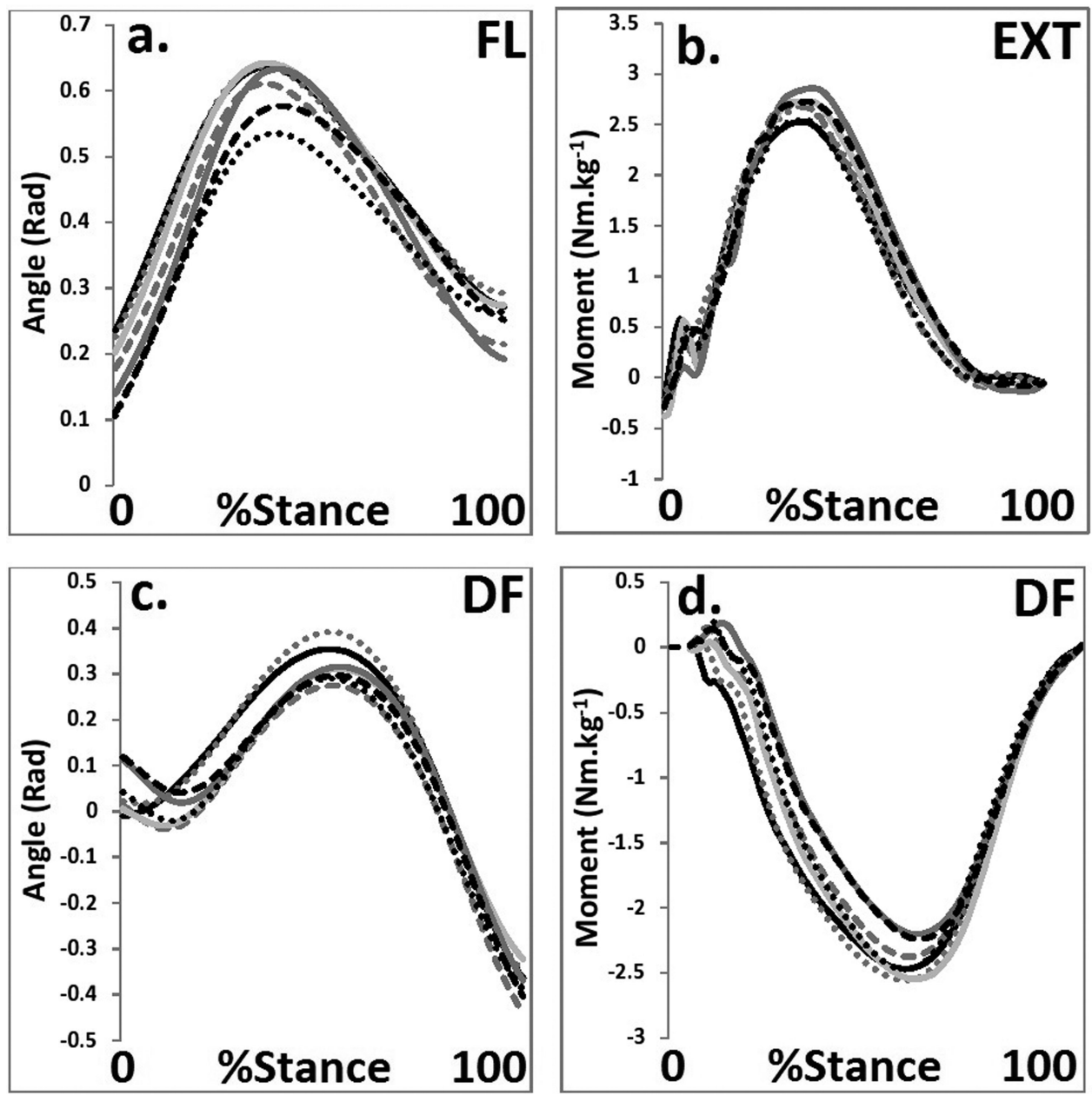

FIGURE 2. Limb and joint stiffness curves as function of footwear: (a) = limb stiffness, (b) = limb displacement, (c) = knee stiffness, $(\mathrm{d})=$ ankle stiffness. barefoot $=$ black, Nike Free $=$ black dash, conventional $=$ dark grey, Vibram five-fingers $=$ light grey, Vivo $=$ dot, Merrell $=$ dark grey dash, Inov- $8=$ dark grey dot.

365 shown that vertical impact loading is greater when running BF (Sinclair, Greenhalgh, et al., 2013; Sinclair, Hobbs et al., 2013). Conversely when habitually BF participants are examined impact loading is greater when running shod (Lieberman et al., 2010; Squadrone \& Gallozzi, 2009). investigation of limb and joint stiffness parameters using participants who habitually run BF.

In conclusion, although differences in running mechanics have been examined extensively, the current knowledge

375 regarding the effects of BFIS on limb and joint stiffness parameters is limited. The present investigation therefore adds to the present knowledge by providing a comprehensive evaluation of the limb stiffness characteristics of running in BF and BFIS. On the basis that peak ankle plantarflexor moment and knee-limb stiffness were shown to be greater in BF and minimalist BFIS and peak knee extensor moment was shown to be larger in $\mathrm{CF}$, the findings from the current investigation may provide further insight into the susceptibility of runners to different injury mechanisms as a function of footwear. The current investigation indicates that running BF and in minimalist BFIS reduces the risk of chronic knee pathologies but also places runners at increased risk from ankle pathologies. Future analyses are nonetheless necessary to provide prospective clinical information of running BF and in BFIS on the etiology of running injuries.

\section{REFERENCES}

Arampatzis, A., Bruggemann, G., \& Metzler, V. (1999). The effect of speed on leg stiffness and joint kinetics in human running. Journal of Biomechanics, 32, 1349-1353.

Blickhan, R. (1989). The spring mass model for running and hopping. Journal of Biomechanics, 22, 1217-1227.

Butler, R. J., Crowell, H. P., \& Davis, I. M. (2003). Lower extremity stiffness: implication for performance and injury. Clinical Biomechanics, 18, 511-517. 
Cappozzo, A., Catani, F., Leardini, A., Benedeti, M. G., \& Della, C. U. (1995). Position and orientation in space of bones during movement: Anatomical frame definition and determination. Clinical Biomechanics, 10, 171-178.

405 De Wit, B., De Clercq, D., \& Aerts, P. (2000). Biomechanical analysis of the stance phase during barefoot and shod running. Journal of Biomechanics, 33, 269-278.

Divert, C., Baur, H., Mornieux, G., Mayer, F., \& Belli, A. (2005). Stiffness adaptations in shod running. Journal of Applied Biomechanics, 21, 311-321.

Dutto, D. J., \& Smith, G. A. (2002). Changes in spring-mass characteristics during treadmill running to exhaustion. Medicine \& Science in Sports \& Exercise, 34, 1324-1331.

Farley, C. T., \& Morgenroth, D. C. (1999). Leg stiffness primarily

415 depends on ankle stiffness during human hopping. Journal of Biomechanics, 32, 267-273.

Ferber, R., Davis, I. M., \& Williams, D. S. (2003). Gender differences in lower extremity mechanics during running. Clinical Biomechanics, 18, 350-357.

420 Granata, K. P., Padua, D. A., \& Wilson, S. E. (2001). Gender differences in active musculoskeletal stiffness. Part II. Quantification of leg stiffness during functional hopping tasks. Journal of Electromyography \& Kinesiology, 12, 127-135.

Hamill, J., Russell, E. M., Gruber, A. H., \& Miller, R. (2011).

425 Impact characteristics in shod and barefoot running. Footwear Science, 3, 33-40.

Kerdock, A. E., Biewener, A. A., McMahon, T. A., Weyand, P. G., \& Herr, H. M. (2002). Energetics and mechanics of human running on surfaces of different stiffnesses. Journal of Applied Physiology, 92, 469-478.

Kulmala, J. P., Avela, J., Pasanen, K., \& Parkkari, J. (2013). Forefoot strikers exhibit lower running-induced knee loading than rearfoot strikers. Medicine \& Science in Sports \& Exercise, 45, 2306-2313.

435 Kyrolainen, H., Belli, A., \& Komi, P. V. (2001). Biomechanical factors affecting running economy. Medicine \& Science in Sports \& Exercise, 33, 1330-1337.

Latash, M. L., \& Zatsiorsky, V. M. (1993). Joint stiffness: Myth or reality? Human Movement Science, 12, 653-692.

440 Lieberman, D. E., Venkadesan, M., Werbel, W. A., Daoud, A. I., D'Andrea, S., Davis, I. S., ... Pitsiladis, Y. (2010). Foot strike patterns and collision forces in habitually barefoot versus shod runners. Nature, 463, 531-535.

Lussiana, T., Hébert-Losier, K., \& Mourot, L. (2014). Effect of minimal shoes and slope on vertical and leg stiffness during running. Journal of Sport and Health Science (In press).

McMahon, T. A., \& Cheng, G. C. (1990). The mechanics of running: how does stiffness couple with speed? Journal of Biomechanics, 23, 65-78.

450 McMahon, J. J., Comfort, P., \& Pearson, S. (2012). Lower limb stiffness: considerations for female athletes. The Strength \& Conditioning Journal, 34, 70-73.
Morin, J. B., Samozino, P., Zameziati, K., \& Belli, A. (2007). Effects of altered stride frequency and contact time on legspring behavior in human running. Journal of Biomechanics, 40, 3341-3348.

Shih, Y., Lin, K. L., \& Shiang, T. Y. (2013). Is the foot striking pattern more important than barefoot or shod conditions in running? Gait \& Posture, 38, 490-494.

Sinclair, J. (2014). Effects of barefoot and barefoot inspired footwear on knee and ankle loading during running. Clinical Biomechanics, 29, 395-399.

Sinclair, J., Edmundson, C. J., Brooks, D., \& Hobbs, S. J. (2011). Evaluation of kinematic methods of identifying gait events during running. International Journal of Sports Science \& Engineering, 5, 188-192.

Sinclair, J., Greenhalgh, A., Edmundson, C. J., Brooks, D., \& Hobbs, S. J. (2012). Gender differences in the kinetics and kinematics of distance running: implications for footwear design. International Journal of Sports Science \& Engineering, 6, 118128.

Sinclair, J., Greenhalgh, A., Edmundson, C. J., Brooks, D., \& Hobbs, S. J. (2013). The influence of barefoot and barefoot -inspired footwear on the kinetics and kinematics of running in comparison to conventional running shoes. Footwear Science, $5,45-53$

Sinclair, J., Hobbs, S. J., Currigan, G., \& Taylor, P. J. (2013). A comparison of several barefoot inspired footwear models in relation to barefoot and conventional and conventional running footwear. Comparative Exercise Physiology, 9, 13-21.

Sinclair, J., Hobbs, S. J., Taylor, P. J., Currigan, G., \& Greenhalgh, A. (2014). The Influence of different force and pressure measuring transducers on lower extremity kinematics measured during running. Journal of Applied Biomechanics, 30, 166-172.

Sinclair, J., Taylor, P. J., Edmundson, C. J., Brooks, D., \& Hobbs, S. J. (2012). Influence of the helical and six available Cardan sequences on 3D ankle joint kinematic parameters. Sports Biomechanics, 11, 430-437.

Sinclair, J., Taylor, P. J., \& Andrews, S. (2013). Influence of barefoot, barefoot inspired and conventional shoes on tibial accelerations and loading kinetics during running in natural rearfoot strikers. Comparative Exercise Physiology, 9, 161-167.

Squadrone, R., \& Gallozzi, C. (2009). Biomechanical and physiological comparison of barefoot and two shod conditions in experienced barefoot runners. Journal of Sports Medicine \& Physical Fitness, 49, 6-13.

Williams, D. S., McClay Davis, I., Scholz, J. P., Hamill, J., \& Buchanan, T. S. (2003). Lower extremity stiffness in runners with different foot types. Gait \& Posture, 19, 263-269.
Received January 19, 2015

Revised March 26, 2015

Accepted April 17, 2015 